\title{
O bem viver: uma proposta para reaprender a sonhar com o mundo
}

\author{
Well-living: a proposal to relearn how to dream about the world \\ Buen vivir: una propuesta para reaprender a soñar con el mundo \\ Conrado Marques da Silva Checchi ${ }^{1}$ \\ Universidade Federal de São Carlos, UFSCAR, São CARLos-SP, BraSIL \\ RESUMO
}

\begin{abstract}
Apresento neste ensaio a perspectiva indígena de Bem Viver como possível anúncio para desconstrução de aspectos coloniais que persistem em moldar de modo exploratório as relações entre seres humanos e meio ambiente, haja vista que cada vez mais tem se propagado sob o horizonte do Planeta Terra um véu de devastação e destruição pelo estímulo desenvolvimentista. Recorro à ecologia dos saberes para pautar um pensamento que renuncie a lógica de apropriação e violência empregada na anulação da diversidade epistêmica dos conhecimentos de diversos povos. Como anúncio, me valho de perspectivas indígenas frente aos sonhos como possibilidade de outro entendimento sobre a vigília, em virtude de neles serem transfigurados os contatos despertos com o mundo, transformando experiências e dotando as dinâmicas sociais com profundos significados. Palavras-chave: Sonho. Bem Viver. Ecologia de Saberes.
\end{abstract}

\begin{abstract}
In this essay I present the indigenous perspective of Well-Living as a possible advertisement for the deconstruction of colonial aspects that persist in shaping the relations between human beings and the environment in an exploratory way, given that a veil of devastation has spread under the horizon of Planet Earth and destruction by developmental stimulus. I resort to the ecology of knowledge to guide a thought that renounces the logic of appropriation and violence used in the annulment of the epistemic diversity of knowledge of different peoples. As an advertisement, I use indigenous perspectives in the face of dreams as a possibility for another understanding of wakefulness, as awakened contacts with the world are transfigured in them, transforming experiences and endowing social dynamics with deep meanings.
\end{abstract}

Keywords: Dream. Well-Living. Ecology of Knowledge.

\section{RESUMEN}

En este ensayo presento la perspectiva indígena de Buen Vivir como un posible anuncio de la deconstrucción de aspectos coloniales que persisten en configurar de manera exploratoria las relaciones entre el ser humano y el medio ambiente, dado que un velo se ha extendido cada vez más bajo el horizonte de Planeta Tierra de devastación y destrucción por el estímulo del desarrollo. Recurro a la ecología de saberes para orientar un pensamiento que renuncia a la lógica de apropiación y violencia empleada en la anulación de la diversidad epistémica del saber de los diferentes pueblos. A modo de publicidad utilizo las perspectivas indígenas frente a los sueños como posibilidad de otra comprensión de la vigilia, pues en ellos se transfiguran los contactos despiertos con el mundo, transformando vivencias y dotando de significados profundos a las dinámicas sociales. Palabras clave: Sueño. Buen Vivir. Ecología de Saberes.

\footnotetext{
1 Doutorando em Educação pelo Programa de Pós-Graduação em Educação da UFSCar. E-mail: conradomarq@gmail.com. ORCID: http://orcid.org/0000-0002-0203-148X.
} 


\section{INTRODUÇÃO}

Neste ensaio indago sobre alternativas de superação do paradigma da modernidade ocidental que tem lançado sob o horizonte do desenvolvimento um véu de devastação e destruição de biomas inteiros do Planeta Terra, reduzido e extinguido a diversidade da fauna e flora ainda existentes. São reflexões amparadas em escritas de indígenas, parentes de distintas etnias que alertam para a necessidade de mudanças radicais de respeito à Natureza e nos indicam que caso não estejamos atentos e transformemos nossa maneira de se relacionar com o mundo, poderemos sofrer cada vez mais impactos que marcarão profundamente nossa existência humana.

Para mudança deste cenário sombrio, recorro a perspectivas indígenas de Bem Viver como mote para a desconstrução de aspectos coloniais que persistem em moldar dicotomicamente as relações entre seres humanos e meio ambiente e neste ensejo, indico a necessidade de atentarmos aos sonhos que, segundo os diferentes autores indígenas que aportaram a presente reflexão, podem ser caracterizados como fortes fios que ligados à atitude de esperançar por melhores tempos, tecem uma realidade cada vez mais sensível e compartilhada, conduta que pode nos levar a transformações significativas de convivência respeitosa entre os seres vivos.

O termo Bem Viver é proveniente das tradições de diferentes povos indígenas habitantes da América do Sul, por se configurar como um conceito, sua tradução busca unificar características presentes na cosmologia de diferentes grupos originários e sugere dentre as várias perspectivas a plenitude do Ser integrado ao meio e toda Vida nele presente; no mundo Quechua, o Bem Viver é reconhecido pelo termo "Sumak Kawsay (a vida em plenitude e harmonia), no mundo Kuna é Baluwaba (a unidade da natureza), e em Aymara, o Suma Oamaña (o bem estar de sua força interna)" (MEJÍA, 2013, p.379).

Apesar das diferentes interpretações, como Alberto Acosta (2016) relata no livro O Bem Viver, não existe uma tradução precisa de um idioma ao outro, aspecto que oportuniza encontrar nas distinções a amplitude da diferença e o enriquecimento de entendimentos, já que ao sobrepor conceitos as visões se homogeneizariam e assim, se tornariam limitadas. Dessa razão podemos apreender que a amplitude de alusões ao conceito de Bem Viver o tornam dinâmico e ao mesmo tempo o assentam sob o solo dos muitos cuidados, tornando-o referencial para o cultivo de outras relações com o ambiente, dos seres consigo mesmos e com outrem, posto que "[...] o núcleo dos debates encerra a dimensão holística de ver a vida e a Pacha Mama em relação e complementaridade uns com os outros" (ACOSTA, 2016, p. 79).

Por partir de diferentes perspectivas indígenas de valoração da vida e que prezam a felicidade como um bem estar com os ecossistemas, o Bem Viver procura estabelecer processos de significação através das circunstâncias sociais e nisto busca conformar espaços que abrigam estruturas simbólicas próprias. Por este motivo, como um projeto de muitas conexões respeitosas entre as diferentes sensibilidades e espiritualidades, $o$ Bem Viver fortalece identidades e aponta para imaginários aglutinadores; em vista disso, credita aos sonhos um vigor essencial por nutrirem a realidade das trocas entre os seres com vínculos sensíveis. Nesse sentido, para melhor entendimento da profundidade das relações estabelecidas com o sonhar, vale ressaltar que para as culturas originárias os sonhos são considerados constituintes das experiências provenientes dos momentos acordados. Como portais que abrem a uma presença desperta e intencional com a história, neles são transfigurados os contatos com o mundo por delimitarem os contornos das relações com as coisas e outrem, provendo assim as dinâmicas cotidianas com densos significados (VIVEIROS DE CASTRO, 2015). 
Contrário a este trajeto orientado por relações vitais com a Natureza, seus ciclos e a imaginação que um viver a ela integrado pode prover, o individualismo apregoado nas cidades tem sido justificado pela ideia de progresso e relacionado preponderantemente com o desenvolvimento sobre todos os anseios da humanidade. Sob o conceito de civilidade, os meios urbanos foram moldados com o distanciamento de todos os feitios que poderiam identificá-lo com o ambiente rural e da figura daquelas/es que retiram da Terra a subsistência, seja a/o camponês/a ou a/o indígena, que em territórios invadidos, saqueados e colonizados como os da América Latina, são alvos de constante extermínio. Nestes termos, a cidade se fez assim, “[...] o lugar privilegiado para não sermos nós mesmos, para deixarmos de nos olhar no espelho, e, ao contrário, para tentarmos viver uma farsa de imitações do que é externo, do 'civilizado', do 'desenvolvido', do moderno-colonial" (IBÁÑ̃EZ, 2016, p. 297).

A cidade por essa forma almejada e ilustrada pela configuração da modernidade, reproduz em sua essência os modos de vida dominantes capitalistas e neste procedimento estratégico, segundo Aníbal Quijano (2013), busca a dispersão das pessoas frente a alternativas a este modelo civilizatório, de modo a universalizar como exemplar uma "[...] conduta egoísta transvestida de liberdade individual, o que na prática equivale à universalização do 'sonho americano' pervertido no pesadelo de brutal perseguição individual de riqueza e poder contra os demais" (QUIJANO, 2013, p.52). Nada contrário a esse trajeto que ruma impenitente à precarização e esvaziamento das potencialidades de significação existencial, mulheres e homens têm sido entregues a escassos ou insuficientes momentos de descanso; envolvidos em um movimento contínuo que tem contribuído com a produção em série de noites mal dormidas e exaurido a busca do prazer pela vida, fazendo com que os sonhos se tornem o abrigo dos medos, como ressalta o indígena Aílton Krenak (2019):

Nosso tempo é especialista em criar ausências: do sentido de viver em sociedade, do próprio sentido da experiência da vida [...] O tipo de humanidade zumbi que estamos sendo convocados a integrar não tolera tanto prazer, tanta fruição de vida. Então, pregam o fim do mundo como uma possibilidade de fazer a gente desistir dos nossos próprios sonhos (p. 13).

À vista disso, reconhecemos nas características da urbanização um modelo que tem na fragmentação dos citadinos um procedimento histórico, uma marca presente nas histórias oficiais que desde a origem da modernidade produz nas formações urbanas a ruptura do ser de sua relação com o meio ambiente. Este procedimento que separou e ainda hoje destitui da cidade o campo, da vigília os sonhos, dos pensamentos o corpo, acompanha todo um histórico de origem colonizadora europeia, a qual junto com seus modos de criar espaços e subjetividades, imprimiu também sua filosofia. Um pensamento que por sua origem epistemológica, remonta ao Iluminismo.

Dentre os teóricos de grande relevância deste período, está o matemático jesuíta europeu René Descartes (1596 - 1650), que compreendeu o mundo como uma máquina e o corpo dos seres humanos como parte deste instrumental mecânico (DUSSEL, 2010). A partir de seu pensamento, como branco, homem e europeu, René Descartes não circunscreveu a um indígena, africano ou asiático, e sob a prerrogativa de indeterminação quantitativa sobre toda a qualidade dos seres, provocou todas as "[...] abstrações ilusórias do 'ponto zero' da subjetividade filosófica moderna e da constituição do corpo como mercadoria quantificável com um preço” (DUSSEL, 2010, p. 354). Princípio epistêmico que acarretou na história o que foi o sistema escravagista ou também o salarial, no capitalismo. 
Dessa maneira, fora difundido pela modernidade protagonizada pela difusão colonialista, um pensamento que distancia o ser de sua corporalidade ao criar um espaço imaginário próprio, discriminado como científico e que tem por princípio a objetificação de toda a Natureza. Por esta pretensão a ciência modernizante se propôs a reduzir toda indagação que poderia haver sobre os organismos vivos a um olhar plano que a tudo disseca, cataloga e discrimina em sua particularidade como se a essência do viver pudesse ser compreendida em uma grande enciclopédia da verdade. Definida como o único padrão de saber, ao incorrer neste intuito, foram-se ignoradas as múltiplas relações de significação e redes de conhecimentos entre os seres. Dessa busca pela lógica ideal, o próprio ser humano foi compartimentado tendo corpo e mente separados (SÉRGIO, 2003), o que configura segundo Ailton Krenak (2019), um contrassenso:

A ideia de nós, os humanos, nos descolarmos da terra, vivendo numa abstração civilizatória, é absurda. Ela suprime a diversidade, nega a pluralidade das formas de vida, de existência e de hábitos. Oferece o mesmo cardápio, o mesmo figurino e, se possível, a mesma língua para todo mundo (p. 12).

Este distanciamento dos pensamentos da realidade vivida tem provocado em nossos dias um enleio das bases materiais que vivemos, uma vez que o constante ritmo de crescimento, motivado pelo progresso da ciência e da técnica, baseado na exploração de recursos naturais tem levado a humanidade a percorrer caminhos alarmantes (BOFF, 2014).

Por essa circunstância, a crença em um desenvolvimento desenfreado regido por um mercado que tudo absorve não tem conduzido e, como atestado nos últimos anos, não conduzirá a condições plenas de bem-estar dos seres humanos, e ainda, se permanecer o aumento do ritmo que a tecnologia moderna tem ofertado na capacidade de transformação do meio ambiente, segundo Eric Hobsbaw (1995), o ser humano terá de tratar o tempo disponível para cuidar do problema em séculos mais do que em décadas por motivo de tamanha alteração já realizada sobre a biosfera terrestre.

Decorrente a essa urgência pelo desenvolvimento desenfreado, vemos espraiado um programa de exploração sistemática do meio ambiente, neste cenário entregue ao acaso e à impermanência, vemos disseminados anúncios fatalistas de devastação que mais imobilizam do que incentivam a mudanças dos quadros e dinâmicas sociais; declarações que junto aos demais fluxos de informações, narram cenários onde o imobilismo é um roteiro pronto e a Natureza parte de um meio ambiente muito distante. Conseguinte a essa circunstância, seres humanos têm tornado o próprio estreitamento dos laços fraternos fragilizados, contornados por posições econômicas e dependentes de aparatos tecnológicos que esvaziam os diálogos do envolvimento construtivo entre comunidades e territórios em que vivem. Frente a essa conjuntura, a humanidade individualizou sua imagem e isolada em busca da sobrevivência nas cidades vemos surgir contextos fadados a uma instabilidade de ânimos e ansiedades que favorecem a um estado inerte de uma vigília incessante, marca inconteste de uma insônia civil predadora de bons sonhos e de compromissos entre os seres.

\section{A MODERNIDADE OCIDENTAL EM COLAPSO}

A degradação ambiental tem expressado certos limites a que o desenvolvimento tem chegado. Como modus operandi ocidental a racionalidade moderna tem sido legitimada como ponto nodal de observação e indagação do mundo, tendo sido forjada 
sob certa concepção que faz da Natureza um objeto a ser apropriado e explorado. Nesse cenário, alguns países de modo geral localizados ao Sul do sistema mundo têm sido enquadrados enquanto fornecedores de produtos primários e circunscritos em uma estratégia que revela certa assimetria com relação aos demais países, reconhecidos como desenvolvidos (ACOSTA, 2016). Boaventura de Sousa Santos (2010) a este respeito comenta sobre as linhas abissais que dividem as nações em Norte e Sul e arregimentaram a cartografia atual moderna de base jurídica e epistemológica, que juntas, atuando através das linguagens da ciência e jurisprudência ocidental, produzem a sub-humanidade do Sul geográfico e metafórico no qual: "A negação de uma parte da humanidade é sacrificial, na medida em que constitui a condição para a outra parte da humanidade se afirmar enquanto universal" (SANTOS, 2010, p. 39).

Dada essa conjuntura, por perpetuar táticas estabelecidas no período colonial e se estruturar como paradigmático, tal padrão de dominação e poder tem sido reconhecido pelo termo colonialidade (QUIJANO, 2013). Por essa ousadia de anulação das muitas experiências situadas nas infinitas conexões entre seres e localidade em que vivem, este procedimento de ocidentalização (SAID, 2007) do mundo tem provocado a propagação de uma compreensão linear do tempo a partir da percepção histórica dos dominadores. Mediante esta ardilosa tática de subjugamento elaborada através do conhecimento científico e burocratização jurídica, o futuro almejado por diferentes grupos periféricos têm se tornado inoportuno mediante a anulação de suas diferentes epistemologias e desconhecimento de suas formas organizatórias, procedimento discriminatório que ao sobrevir como fórmula de um destino pronto, sobrepesam as sociedades com o desprezo pelas condições do presente (SANTOS; MENESES, 2010).

A marginalidade que os poderosos protagonistas da modernização procuram incutir, reprimindo toda e qualquer mudança social, tem criado uma situação de expropriação da dignidade do viver fazendo da Terra um ambiente hostil aos seres humanos que, por perderem as condições de significá-la, tornam-se estranhos ao próprio ambiente vivido. Esse alheamento decorrente do mundo invertido imposto inicialmente pelo colonizador europeu (GALEANO, 2010) tem se propagado e mantido por meio de diferentes acordos econômicos, culminando no que atualmente é reconhecido pelos moldes neoliberais, o qual tem no desenvolvimento a premissa para a intervenção e condução de apaziguamento sobre todo conflito nos diferentes países do globo. A distinção originária deste modelo, marcada outrora entre colonizadores e colonizados, desenvolvidos e subdesenvolvidos, atualmente é marcada predominante por todo o projeto de modernização, o qual desde o início de sua expansão tem atribuído aos diferentes países as categorias de serem centrais ou periféricos deste programa, colocando à margem todos os que não são reconhecidos pelas nações do centro da totalidade dominante (DUSSEL, 2016).

Tais países fora do eixo da primazia do primeiro mundo, diante da marginalização a que são submetidos, resistem às sombras daqueles que orientam setores econômicos, políticos, científicos, filosóficos, artísticos e educativos, tendo suas experiências desperdiçadas ao serem invisibilizadas e negadas (SANTOS, 2010). Nesse quadro, para adentrar na esteira do desenvolvimento, tem sido empregada a estratégia de submissão às grandes corporações transnacionais, criadoras mundiais de concentração de riqueza pela monopolização e aplicação do capital através de potências industriais. Tal tática envolve, como um engodo, acordos de uma pretensa economia de bem-estar mundial, mas que na prática, exerce a dominação de grande maioria da população que não tem partilhado das benesses provenientes dos acordos político-econômicos (SANTOS; MENESES, 2010; ESCOBAR, 2014). 
Como fruto de tal conjuntura está a realidade do desemprego e do subemprego aos esfarrapados do mundo. Por terem sua força de trabalho aliadas a maquinarias tecnológicas que vem extinguindo cada vez mais cargos, o métier do trabalhador fabril tem se contraposto e tornado o do instrumento sobre a máquina, já que "[...] criado para substituir o escravo, o instrumento tecnológico acabou por escravizar o ser humano ao visar a produção em massa" (BOFF, 2014, p. 144).

Sendo confundido como objeto, obsoleto ao se colocar diante a maquinaria do desenvolvimentismo, o ser humano se rende a uma ciência que tem como destino o lucro e é vulnerabilizado pela pretendida tecnologia propulsionadora de um almejado progresso.

Diante deste panorama, o consumo atinge a centralidade dos processos de composição do viver e o conhecimento, algo que pode se comprar e vender, aspecto que tem feito do mundo um lugar de domínio das visualidades, das marcas e do marketing. Comerciantes e publicitários são os responsáveis pela confiança na sedução das ofertas e na crença do "[...] impulso de seus clientes potenciais de estar sempre um passo à frente dos outros e de levar vantagem" (BAUMAN, 2010, p.36).

Decorrente ao mercado global competitivo organizado pelas normas capitalistas, vemos surgir produtos oriundos de um ambiente árido da mão humana, de uma sociedade sem alma (sem o feitio sensível do traço de uma cultura arraigada ao chão de um lugar) (QUIJANO, 2013).

Conseguinte ao estrago mobilizado pela aculturação urbano industrial, como marca de sua presença destrutiva, sobram os resíduos de todos os tipos provenientes do acúmulo material desmesurado.

Como uma tática de dispersão e alienação dos seres humanos diante de outrem e do meio em que vivem, programas que visam cuidados ao meio ambiente, também conhecidos como sustentáveis ${ }^{2}$, públicos ou financiados pelas grandes corporações, não acompanham reflexões sobre a redução do consumo ou responsabilização das empresas com uma logística reversa ${ }^{3}$ que inclua profissionais da reciclagem, Catadoras/es que na berlinda da inclusão trabalhista, sofrem como em uma luta pela sobrevivência (CHECCHI, 2018).

Por essa postura imponderada ao consumismo, seres humanos têm deixado distante a reflexão sobre o bioma que se olha, o chão em que se pisa, o cheiro que se sente e a vida que nele habita para torná-la mais um item de visualidade, uso e descarte dentro de toda a maquinaria-mundo disponível, lugar onde os interesses se renovam incessantemente mediante aparatos da lógica mercadológica do capital exploratório.

Esta trama muito bem calculada pelo desenvolvimento tem feito com que ao invés da possível liberdade gerada pelas invenções, caiamos em um laço que dificilmente se desatará caso não rompamos com a limitação da novidade em constante mutação para nos religarmos à essência fundadora de nossa interioridade criativa e de completa satisfação, o Amor como atenção a toda Vida-com-a-Terra (BOFF, 2014).

\footnotetext{
2 Por trás de muitos destes projetos encontra-se a marca que os inserem na norma moderna do ecologicamente correto: manutenção dos padrões nocivos do consumismo (atrelado à lógica do aumento contínuo da produção capitalista) gerando uma grande quantidade de resíduos sólidos nas cidades. Neste padrão de organização de uma insustentabilidade, apenas os materiais que reúnem condições de atender ao mercado (baixo custo, grande oferta de matéria prima e mercado consumidor garantido) é que se tornam alvos da indústria da reciclagem. Nesta lógica de procedimento mercantil, os impactos ambientais que os resíduos podem ou não gerar ao meio ambiente são irrelevantes. Se a reciclagem não provê o lucro, o melhor a ser feito com os resíduos é enterrá-los (Leal et al., 2002).

${ }^{3}$ Composta de um conjunto de ações que tem como finalidade viabilizar a restituição dos resíduos sólidos ao setor empresarial para seu reaproveitamento.
} 


\section{O BEM VIVER}

Questionar a palavra desenvolvimento perpassa visualizar em sua projeção ocidental moderna, aspectos contraditórios a toda noção comunitária que venhamos a ter. Superar esta condição de opressão para valorização do viver, nos alerta Paulo Freire (2011), implica a necessidade de tratarmos das coerências entre o vivido e o imaginado, entre a fala e as ações, porquanto que "[...] nenhum colonizado, como indivíduo ou como nação, sela sua libertação, conquista ou reconquista sua identidade cultural sem assumir sua linguagem, seu discurso e por eles ser assumido" (FREIRE, 2011, p.243).

Sendo assim, buscar por uma ampliação do olhar que categorize o saber para além de noções cientificistas e técnicas, pode nos representar uma significativa mudança nos modos de pensar as esferas de atuação humana que rompam com as divisões entre prática e teoria.

Boaventura S. Santos (2010), almejando uma mudança radical nos modos de conceber o conhecimento, propõe uma Ecologia dos Saberes a partir de uma copresença radical, a qual "[...] implica conceber simultaneidade como contemporaneidade, o que só pode ser conseguido abandonando a concepção linear de tempo" (SANTOS, 2010, p. 53). Proposta que intenciona uma contemporaneidade de conhecimentos para valorização de saberes e distintas historicidades que simultaneamente desvelam mundos e diferentes possibilidades de Ser.

Ao objetivar um pensamento que renuncie a lógica de apropriação e violência empregada na anulação da diversidade epistêmica dos conhecimentos, a Ecologia dos Saberes, por superar comportamentos discriminatórios entre conhecimentos, é configurada pela "[...] pluralidade de formas de conhecimento além do conhecimento científico" (SANTOS, 2010, p. 54). Orientação que aspira impulsionar o posicionamento político de povos e visões diferenciadas de mundo contrárias à globalização hegemônica, por ser pautada em saberes de bases plurais e de proposição a intervenção no real.

Para o indígena e ativista Aílton Krenak (2019),

[...] a ecologia dos saberes deveria também integrar nossa experiência cotidiana, inspirar nossas escolhas sobre o lugar em que queremos viver, nossa experiência como comunidade. Precisamos ser críticos a essa ideia plasmada de humanidade homogênea na qual há muito tempo o consumo tomou o lugar daquilo que antes era cidadania (p. 12).

Eduardo Gudynas (2009), visando a uma Ecologia de Saberes, propõe que uma alternativa à modernidade deve abrir "[...] espaços para novas formas de valoração ambiental e articulação com os saberes indígenas" (GUDYNAS, 2009, p. 34), e sugere que para uma verdadeira libertação dessas amarras modernizantes ocidentais, necessitamos de um rumo biocêntrico, valoroso sobre toda a vida, e não apenas antropocêntrico.

Muitas etnias indígenas presentes entre os grupos ameríndios possuem em sua cosmovisão alternativas que partem da unidade entre seres humanos e Natureza para pautar perspectivas de igualdade da essência da vida entre todos/as, onde a integralidade da forma do viver é concebida em cuidados amplos e responsáveis com a satisfação de um bem comum, um Bem Viver (ACOSTA, 2016).

Os países Equador e Bolívia, através de suas Constituições, representam um passo além por nelas definirem os Direitos da Natureza, ou seja, estabeleceram um marco na Humanidade por reconhecerem a Natureza não mais como objeto, mas um ser de direitos e digno de restauração integral (em caso de degradação) (ACOSTA, 2016). 
Nestes termos a Natureza em seus direitos não se torna objeto intocável que nem mesmo pode ser usufruída para alimentação, mas ao contrário, ao ser representada por pessoas e comunidades, povos e nações, seus ciclos vitais e processos evolutivos são tidos como essenciais para seu funcionamento. Ao ser reconhecida por lei, criam-se oportunidades de reinvindicação para que o foco de cuidados com a Vida estejam para além de temas próprios ao direito ambiental, no que tange as reservas ambientais, ou nos cuidados especiais com espécies em extinção, mas na responsabilidade em assegurar a constância da sobrevivência dos ecossistemas com suas espécies nativas e dos próprios seres humanos (ACOSTA, 2016).

\section{SONHOS COMPARTILHADOS: UM CAMINHO PARA O BEM-VIVER}

O indígena da etnia Krenak, Aílton Krenak (2020), nos alerta para uma necessária reconfiguração de nossa percepção em relação ao mundo caso queiramos a construção de outra realidade em que a Vida, encontrada na essência de todo ser, fauna e flora, seja tida em reverência como doadora de todo equilíbrio e vitalidade que necessitamos para nossa própria realização. Para esta mudança, o autor destaca que os sonhos são elementares deste processo de reconfiguração de valores, pois partem das dinâmicas de convivência entre os seres, por isso devem deixar de ser uma atividade amortecida, inerte e derivada de um tempo apagado de nossas reflexões. Ou seja, os sonhos não devem ser tidos como resquícios de uma memória particular feita de experiências singulares e próprias apenas àquele que sonha, mas para que sejam potentes e parte de uma transformação vital, decorre concebê-los como um convite à partilha:

[...] a referência a essa instituição do sonho não como uma experiência onírica, mas como uma disciplina relacionada à formação, à cosmovisão, à tradição de diferentes povos que têm no sonho um caminho de aprendizado, de autoconhecimento sobre a vida, e a aplicação desse conhecimento na sua interação com o mundo e com as outras pessoas (KRENAK, 2019, p. 25).

Os sonhos por esta concepção, por serem constituídos por todo um contexto em imanência, não poderiam se esgotar apenas nas relações provenientes da dimensão cultural humana.

Para que avancemos neste sentido, Humberto Maturana e Francisco Varela (2001; 2003) apresentam noções muito profícuas acerca da constituição da compreensão humana a partir do conceito de autopoiese. Segundo os autores, a organização autopoiética se configura pela característica dos organismos vivos produzirem a si mesmos continuamente. Nestes termos, todo ser vivente e o meio em que vive modificam-se de forma congruente, ambos como agentes, produtores e produto de uma mesma estrutura de relações organizativas da existência.

A partir desta teoria, podemos conceber que o meio produz mudanças nas estruturas dos sistemas vivos em virtude de que os organismos estão em contínua relação uns com os outros, de modo que um influencia ao outro reciprocamente em um envolvimento de compensação. Como sistema vivo, toda estrutura que liga um organismo ao outro é mutável, resultado e causa de modificações contínuas, sendo sua desorganização o limite para as mudanças e cujo fim, redunda em sua morte (MATURANA; VARELA, 2003).

Isto posto, podemos conceber que os contornos da existência são pautados em relações compensatórias entre os seres vivos e o meio, e que uma maior atenção para tal compreensão pode ampliar a percepção que tenhamos sobre o viver, por tornarem 
necessários o reinventar da Vida através das múltiplas relações de presença entre os seres e por serem constituintes das emoções provenientes da alteridade entre todos, seres humanos, fauna e flora (MATURANA; VARELA, 2001).

Nesse ponto, para melhor compreensão da constituição de nossa percepção do mundo, Maurice Merleau-Ponty (1994) ressalta que esta é proveniente de nosso contato com as coisas e a consciência que possuímos delas, ou antes, em outras palavras, a experiência que com elas constituímos, uma vez que nosso Ser é feito de um comunicarse interiormente com o mundo e com os outros, cabendo a nós a alternativa de "[...] ser com eles em lugar de estar ao lado deles" (MERLEAU-PONTY, 1994, p. 142). Desta forma podemos concernir que o mundo que vivemos é resultado de nossas percepções e a consciência que delas podemos ter; é decorrente de nossa intencionalidade em meio às coisas, uma potência de projeção que oportuniza nos lançarmos frente às coisas e ordenar a matéria da experiência. Desta noção, para que haja consciência:

[...] é preciso exista um algo do qual ela seja consciência, um objeto intencional, e ela só pode dirigir-se a este objeto enquanto se 'irrealiza' e se lança nele, enquanto está inteira nesta referência a... algo, enquanto é um puro ato de significação. Se um ser é consciência, é preciso que ele seja apenas um tecido de intenções. Se ele deixa de se definir pelo ato de significar, ele volta a cair na condição de coisa, a coisa sendo justamente aquilo que não conhece, aquilo que repousa em uma ignorância absoluta de si e do mundo, aquilo que por conseguinte não é um 'si' verdadeiro, quer dizer, um 'para si', e só tem a individuação espaço-temporal, a existência em si (MERLEAU-PONTY, 1994, p. 172).

Aílton Krenak (2019) em seus escritos nos diz que para podermos reconfigurar a relação com os sonhos na perspectiva indígena uma outra percepção de mundo é necessária, em que novos valores estão implicados e exigem de nós um esforço, um deslocamento para que os ímpetos de classificação e domínio sobre todas as coisas deixem de fazer parte de nossas práticas. Entendimento que envolve o respeito de se conceber em integridade e completude com as virtudes que proveem da vitalidade que anima todos os seres vivos. Nós modernos, como Eduardo Viveiros de Castro (2015) escreveu, temos de percorrer um longo caminho caso queiramos transcender e ir além nesse denso e sensível entendimento, dado que

[...] ao adentrarmos o espaço da exterioridade e da verdade - o sonho -, só conseguimos ver reflexos e simulacros obsedantes de nós mesmos, em lugar de nos abrirmos à inquietante estranheza do comércio com a infinidade de agências, ao mesmo tempo inteligíveis e radicalmente outras, que se encontram disseminadas pelo cosmos (VIVEIROS DE CASTRO, 2015, p. 38).

Os sonhos, como parte das relações complexas entre os seres em constante movimento com o mundo são axiais, eixos formadores de percepções e valores, não apenas de lentes oníricas de um mundo determinado, mas corporalidade emergente, em contínua formação com outrem, que está intimamente ligado por uma conexão de comunhão.

Aílton Krenak (2019), para dizer da experiência do sonhar indígena e trazer a profundidade desta experiência, relata a falta de palavras para discriminar aquilo que, para visão ocidental, facilmente é descrita pelo termo Natureza, mas que pela impossibilidade de ser experimentada, sua essência é inominável: 
De que lugar se projetam os paraquedas? Do lugar onde são possíveis as visões e o sonho. Um outro lugar que a gente pode habitar além dessa terra dura: o lugar do sonho. Não o sonho comumente referenciado de quando se está cochilando ou que a gente banaliza "estou sonhando com o meu próximo emprego, com o próximo carro", mas que é uma experiência transcendente na qual o casulo do humano implode, se abrindo para outras visões da vida não limitada. Talvez seja outra palavra para o que costumamos chamar de natureza. Não é nomeada porque só conseguimos nomear o que experimentamos. O sonho como experiência de pessoas iniciadas numa tradição para sonhar (KRENAK, 2019, p. 32).

Daniel Munduruku (2019) descreve que ao observarmos o comportamento da Natureza poderemos notar que sua essência tende sempre ao equilíbrio, nela, todos os organismos vivem conjuntamente e necessitam uns dos outros, pois criam nesta medida espaços onde todos são amparados e regidos pelos ciclos da existência de modo que, caso uma das espécies que compartilham desta rede vital deixe de existir, por motivo de algum impacto ou extinguido por algum outro ser, o desequilíbrio provocado abarca a todos e a harmonia até então dinamizada é abalada, dando sequência a outro processo de adaptação, dinamizado pelas espécies e meio do sistema envolvente até o equilíbrio conseguinte. Disso podemos aprender que quanto maior a (bio)diversidade, mais chance terá um (eco)sistema de se reequilibrar, ou seja, quanto mais Vida nele houver, maior será sua resiliência.

Nesse sentido, a estabilidade de um sistema sobreviver depende intimamente de sua diversidade, de sua cooperação em uma dinâmica em que todos viventes estão implicados e interagem entre si. Aí que não caberia nessa dinâmica integradora, o emprego de noções como a competição, relacionadas à cultura humana, para as projetar na Natureza. Humberto Mariotti (1999) a esse respeito expõe o quão deficitário e limitante é tal procedimento:

Reafirmo que não existe competição (no sentido predatório do termo) entre os seres vivos não-humanos. Quando o homem chama determinados animais de predadores está antropomorfizando-os, ou seja, projetando neles uma condição que lhe é peculiar. Como não competem entre si, os sistemas vivos não-humanos não 'ditam' uns aos outros normas de conduta. Mantidas as condições naturais, entre eles não há comandos autoritários nem obediência irrestrita. Os seres vivos são sistemas autônomos, que determinam o seu comportamento a partir de seus próprios referenciais, isto é, a partir de como interpretam as influências que recebem do meio. Se tal não acontecesse, seriam sistemas sujeitados, obedientes a determinações vindas de fora (MARIOTTI, 1999).

As pressões incorporadas por habitarmos as cidades tendem a condicionar a negação das potencialidades que a coexistência com as variadas formas de vida ao interagirem, seres humanos, fauna e flora, poderia oportunizar. Davi Kopenawa e Bruce Albert (2015) acerca disto, apontam que para os citadinos “[...] não é possível conhecer as coisas do sonho. Nelas não conseguem ver as imagens dos espíritos da floresta e dos ancestrais animais" (KOPENAWA; ALBERT, 2015, p. 437).

De modo distinto, os sonhos pelas muitas perspectivas originárias, podem apresentar soluções inéditas e colaborativas, solidárias por serem frutos da cooperação e feitos por muitas mãos em conjunto com uma localidade, solo onde as águas são preciosas e signo de vitalidade e abundância, por isso dignas de todo cuidado, assim como os animais e plantas. Sonhos em que se fazem presentes os diferentes seres cujos nomes poderíamos reconhecer não apenas pelos nomes, mas pela distinção das cores e cantos, rastros, cheiros e odores sob territórios com horizontes ao sol ou estrelas que 
podem embelezar um viver integral, um Bem Viver ligado àquilo que anima a semente a ponto de despertá-la da terra.

Para que consideremos os sonhos como constituintes de nossas vidas, fonte de sabedoria da qual emana o Bem Viver, o indígena Davi Kopenawa e o antropólogo Bruce Albert (2015), alertam no livro A queda do céu acerca daquilo que emerge quando estamos dormindo e nos mostram que estes pensamentos são provenientes de nossas preocupações, as quais, por permanecerem fixas no individualismo, podem nos revelar as espessas teias que nos prendem e nos mantêm separados das possibilidades de vivermos uma vida cada vez mais compartilhada, íntegros com a Natureza, doadora de toda vida.

São as palavras que escutamos no tempo dos sonhos e que preferimos, pois são nossas mesmo. Os brancos não sonham tão longe quanto nós. Dormem muito, mas só sonham com eles mesmos. Seu pensamento permanece obstruído e eles dormem como antas ou jabutis. Por isso não conseguem entender nossas palavras (KOPENAWA; ALBERT, 2015 p. 390).

Pela compreensão indígena, os sonhos são parte de um presente irrepetível, compartilham da essência vital e mutável que anima, dá cheiro, cor e som a todos os seres e plantas, sendo assim ligados às infinitas interações que a Vida proporciona em seus mistérios. $\mathrm{O}$ sonhar indígena toca ao presente nos momentos despertos, trazendo respostas ao dia a dia, pautando a vida não em uma linearidade em termos de perspectivas que rumam do presente ao futuro, mas em uma circularidade. Para exemplificar esta outra forma de apreensão da vida integral com o meio, dos sonhos e vigília, Daniel Munduruku (2019) recorre à infância:

[...] a criança tem um pensamento circular ancestral. Dentro dela estão as
lembranças que carrega consigo e que resumem a história de toda a sua gente.
[...] Prefiro pensar que todos nós trazemos escritas em nossos corpos as
histórias de outra gente que nos antecedeu. O que quero dizer é que o
pensamento circular da criança permite que ela visualize pontos na história
narrada que se encontram invisíveis aos olhos o contador, pois o contador
está sob a lógica da linearidade. Quem conta a história não consegue
compreender que a fala precisa dar muitas voltas para que o espírito encontre
sentido (MUNDURUKU, 2019, p. 29).

Ao pensarmos a circularidade e as histórias que emergem das relações entre pessoas e Natureza, podemos enxergar o quão profícua é a oportunidade do convívio respeitoso e harmonioso entre os seres, aspecto que dota a Vida com oportunidades, aberturas ao vindouro não como receitas para o sucesso, mas de horizonte que se almeja ao tocar o agora. Presente imerso em suas diferenças e contradições, diverso, pois mais do que objetos ao nosso redor, bens materiais e serviços, temos a existência em constante construção onde pessoas, crianças e idosos, animais, plantas, rios e oceanos podem cada vez mais serem compreendidos em interações, compondo um universo progressivamente sensível e respeitoso com a diferença.

O ser humano ao se distanciar de um contato criador com o mundo e permanecer compromissado apenas com respostas aos seus desejos particulares, se esteriliza de um contato vigoroso com o meio, acabando por se valer e sonhar tão-somente com uma vitória sobre o meio e suas adversidades. Um engano, pois ainda que para alguns sonhar seja apenas uma desconexão da realidade,

[...] também podemos encontrar quem não veria sentido na vida se não fosse informado por sonhos, nos quais pode buscar os cantos, a cura, a inspiração e 
mesmo a resolução de questões práticas que não consegue discernir, cujas escolhas não consegue fazer fora do sonho, mas que ali estão abertas como possibilidades (KRENAK, 2019, p. 25).

Aílton Krenak (2019), dessa forma, anuncia como um alerta ao dizer que nossa existência é subjetiva, é poética, por isso necessita ser compartilhada e pautada em noções comunitárias e respeitosas para que a existência seja algo a ser priorizada entre todas/os, eterna em sua constituição vital e dessa forma não estejamos como que em sobre-vivência diante da maior graça que possuímos, mas com-as-muitas-vivências para manutenção do bem mais precioso que somos dotados.

Assumir os sonhos na perspectiva indígena perpassa assumirmos o Bem-Viver como reflexão e prática paradigmática, acatando nesta ação o mistério do Viver como um cuidado, um zelo expresso pela doação, oportunidade única de estarmos como dádiva sendo-com-os-outros-ao-mundo (RODRIGUES; GONÇALVES JUNIOR, 2009). Explicação que está longe de qualquer alcance, mas que no contato, como um alento denso de significados que nos satisfazem e unem à essência do viver, pode se desvelar em presença responsável, amorosa, terna e única com toda Vida.

\section{CONSIDERAÇÕES FINAIS}

Atualmente em todas suas tramas, a modernidade se amplifica por diferentes artefatos que interagem e intumescem nossas sensibilidades, fazendo com que a construção daquilo que temos como ação no mundo seja mediada pelos diferentes recursos tecnológicos, novidades últimas do universo científico.

Os estímulos decorrentes da vida nas cidades modernas, dessa forma, convergem espontaneamente para a lógica do mercado capitalista, cumprindo com sua marca e origem colonial por deixarem como procedimento padrão a falta de indagação ao que temos para ser vivido. Como resposta alheia proveniente de um racionalismo burocratizador e uma tecnocracia onipotente, a perene anestesia sensível que o consumismo insaciável de bens e serviços pode proporcionar.

Para construção de alternativas frente a este movimento centrado no ser humano, neste ensaio foram apresentadas pistas para uma virada biocêntrica (GUDYNAS, 2009; 2016) a partir de uma breve incursão sobre o sonhar através da concepção do Bem Viver, tendo como referência autores indígenas (KRENAK, 2019; 2020; MUNDURUKU, 2019; KOPENAWA; ALBERT, 2015).

Vislumbramos assim, que os sonhos ao serem compartilhados no dia a dia são fundamentais para prover profundas mudanças no entendimento da vigília e que ao atentarmos para eles, podem nos aproximar de buscas esperançosas e mais cuidadosas com a Natureza e toda biosfera.

Considerar o sonhar como elemento fundamental das maneiras que concebemos o cotidiano, perpassa compreendê-lo como decorrente do contato com o meio que possuímos e atenções que cultivamos. Os sonhos, ao serem destacados como parte significativa de nossa experiência, conforme diferentes etnias originárias explicitam, podem desvelar contradições que têm de serem superadas em nível do bem comum, principalmente em questão de nosso reconhecimento e relação com os demais seres vivos, fauna e flora. Deste atributo, podemos suplantar a muitas outras condições que inferiorizam a humanidade e reduzem a alegria do amor compartilhado apenas a um bem comprado, um serviço utilizado ou um tempo em um lugar que só o dinheiro pode proporcionar. 
Reinventar a Vida nesta perspectiva compartilhada nos remete ao cultivo de outras relações com o mundo em que o destino dos anseios culmina no suprimento de expectativas respeitosas entre todos os seres e cuja coexistência harmônica possibilitanos uma reaprendizagem do que é o sonhar. Por esse propósito, ao fazer com que nossas experiências não sejam fechadas em reflexões a respeito de posses, bens e outros materiais provenientes da cultura humana, mas embasada cada vez mais em um Bem Viver, os sonhos como integrantes e integradores das relações com outrem, sendo eles um pássaro, um lago, uma flor, uma montanha ou um ser humano, podem nos conduzir a um maior contato com a essência da maior novidade que somos portadores, a existência.

A partir desta percepção, arraigada nos distintos povos originários, sonhar com toda vida sob a biosfera poderá, como alternativa, nos constituir de corpo íntegro, situado no mundo, imerso em situações vívidas e também contradições que exigem de nós perseverança, fé nas muitas pessoas, animais, plantas e árvores, relevos, água, chuva e neve, para que ao compartilharmos sonhos, possamos juntos buscar e almejar condições de vê-los realizados no tocante do agora. Sonhos que nos fazem satisfeitos por estarmos uns-com-os-outros vivendo não apenas nossas demandas, mas aquilo que a Terra nos propõe por ser provedora de todo ser vivente e merecedora de todo cuidado.

\section{REFERÊNCIAS}

ACOSTA, A. O bem viver: uma oportunidade para imaginar outros mundos. São Paulo: Autonomia Literária, 2016.

BAUMAN, Z. Capitalismo parasitário: e outros temas contemporâneos. Rio de Janeiro: Zahar, 2010.

BOFF, L. Saber cuidar: ética do humano - compaixão pela terra. 20. ed. Petrópolis: Vozes, 2014.

CHECCHI, C. M. S. Mulheres catadoras fotografando o mundo vida, revelando processos educativos. 2018. 344 f. Dissertação (Mestrado em Educação) - Centro de Educação e Ciências Humanas, Universidade Federal de São Carlos, São Carlos, 2018.

DUSSEL, E. Meditações anticartesianas sobre a origem do antidiscurso filosófico da modernidade. In: SANTOS, B. S.; MENESES, M. P. (org.). Epistemologias do sul. São Paulo: Cortez, 2010. p. 31 - 83.

DUSSEL, E. Transmodernidade e interculturalidade: interpretação a partir da filosofia da libertação. Revista Sociedade e Estado, v. 31; n. 1, p.51-73, jan./abr. 2016.

ESCOBAR, A. Sentipensar con la tierra: nuevas lecturas sobre desarrollo, territorio y diferencia. Medellín: Ediciones UNAULA, 2014.

FREIRE, P. Pedagogia da esperança. 17. ed. Rio de Janeiro: Paz e Terra, 2011.

GALEANO, E. De pernas pro ar: a escola do mundo ao avesso. Porto Alegre: L\&PM Pocket, 2010.

GUDYNAS, E. Transições ao pós-extrativismo: sentidos, opções e âmbitos. In: DILGER, G.; LANG, M.; PEREIRA FILHO, J. (orgs.). Descolonizar o imaginário: debates sobre pós-extrativismo e alternativas ao desenvolvimento. São Paulo: Fundação Rosa Luxemburgo, 2016. p. 174-212.

GUDYNAS, E. La ecologia política del gíro biocéntrico em la nueva constituición del Ecuador. Revista de Estudios Sociales, Bogotá, n. 32, p. 34-46, abr. 2009.

HOBSBAWM, E. Rumo ao milênio. In: HOBSBAWM, E. A era dos extremos: o breve século XX, 1914-1991. 2. ed. SãoPaulo: Companhia das Letras, 1995. p. 537-562. 
IBÁÑEZ, M. R. Ressignificando a cidade colonial e extrativista: bem viver a partir de contextos urbanos. In: DILGER, G.; LANG, M.; PEREIRA FILHO, J. (orgs.). Descolonizar o imaginário: debates sobre pós-extrativismo e alternativas ao desenvolvimento. São Paulo: Fundação Rosa Luxemburgo, 2016. p. 296-333.

KOPENAWA, D.; ALBERT, B. A queda do céu: palavras de um xamã yanomani. 6. reimp. São Paulo: Cia. das Letras, 2015.

KRENAK, A. O amanhã não está à venda. São Paulo: Companhia das Letras, 2020.

KRENAK, A. Ideias para adiar o fim do mundo. São Paulo: Cia. das Letras, 2019.

LEAL, A. C.; THOMAZ JÚNIOR, A.; ALVES, N.; GONÇALVES M. A.; DIBIEZO, E. P.; CANTÓIA, S.; GOMES, A. M.; GONÇALVES, S. M. M. P. S.; ROTTA, V. E. A reinserção do lixo na sociedade do capital: uma contribuição ao entendimento do trabalho na catação e na reciclagem. Terra Livre, São Paulo, v. 18, n. 19, p. 177-190, jul.-dez. 2002.

MARIOTTI, H. Autopoiese, cultura e sociedade. 1999. Disponível em: http://escoladedialogo.com.br/escoladedialogo/index.php/biblioteca/artigos/autopoiese-cultura-esociedade/. Acesso em: 18 jul. 2021.

MATURANA, H. R.; VARELA, F. J. De máquinas y seres vivos: autopoiesis: la organización de lo vivo. 6. ed. Buenos Aires: Lumen, 2003.

MATURANA, H. R.; VARELA, F. J. A árvore do conhecimento: as bases biológicas da compreensão humana. São Paulo: Pala Athenas, 2001.

MEJÍA, M. R. Pósfácio - la educacion popular: una construcción colectiva desde el sur y desde abajo. In: STRECK, D. S; ESTEBAN, M. T. Educação popular: lugar de construção social e coletiva. Petrópolis: Vozes, 2013. p. 369-398.

MERLEAU-PONTY, M. Fenomenologia da percepção. São Paulo: Martins Fontes, 1994.

MUNDURUKU, D. Das coisas que aprendi: ensaios sobre o bem-viver. 2. ed. Lorena: DM Projetos Especiais, 2019.

QUIJANO, A. Bem viver: entre o desenvolvimento e a des/colonialidade do poder. Revista da Faculdade de Direito da UFG, v. 37, n. 1, p. 46-57, 2013.

RODRIGUES, C.; GONÇALVES JUNIOR, L. Ecomotricidade: sinergia entre educação ambiental, motricidade humana e pedagógica dialógica. Motriz, v.15, p. 987-995, 2009.

SAID, E. Orientalismo: o oriente como invenção do ocidente. São Paulo: Companhia das Letras, 2007.

SANTOS, B. S. Para além do pensamento abissal: das linhas globais a uma ecologia de saberes. In: SANTOS, B. S.; MENESES, M. P. (org.). Epistemologias do sul. São Paulo: Cortez, 2010. p. 31-83.

SANTOS, B. S.; MENESES, M. P. (org.). Epistemologias do sul. São Paulo: Cortez, 2010.

SÉRGIO, M. Alguns olhares sobre o corpo. Lisboa: Instituto Piaget, 2003.

VIVEIROS DE CASTRO, E. Prefácio: o recado da mata. In: KOPENAWA, D.; ALBERT, B. A queda do céu: palavras de um xamã yanomani. 6. reimp. São Paulo: Cia. das Letras, 2015. p. 11-42.

Recebido em: 30 nov. 2020.

Aprovado em: 07 set. 2021.

Motricidades: Rev. SPQMH, v. 5, n. 2, p. 250-263, maio-ago. 2021 | ISSN 2594-6463 |

DOI: http://dx.doi.org/10.29181/2594-6463-2021-v5-n2-p250-263 